\title{
Research article \\ Altered levels of fructosamine and glycated haemoglobin (HbA1c) in thyroid disorder patients without diabetes mellitus-A cross sectional study
}

\author{
G. Sajjan Sangamma ${ }^{1}$, S. Sonoli Smita ${ }^{2}$, Angadi Naveen ${ }^{3}$ \\ ${ }^{1}$ Assistant Professor, ${ }^{2}$ Professor, Department of Biochemistry, ${ }^{3}$ Professor, Department of Medicine, KLE Academy of Higher \\ Education and Research,J.N.Medical College,Nehru Nagar,Belagavi,590010, Karnataka, India
}

(Received: November $2020 \quad$ Revised: March $2021 \quad$ Accepted: March 2021)

Corresponding author: Sangamma G. Sajjan. Email: 7jyothigs@gmail.com

\begin{abstract}
Introduction and Aim: Co-existence of thyroid disorder and Diabetes Mellitus is no more a coincidence. The cause and impact of thyroid disorder on glucose levels or vice versa is a well -established fact.Hence in this study we wanted to know the glycemic status by estimating fructosamine and glycated hemoglobin of the newly diagnosed thyroid patients without diabetes mellitus. The aim of the study was to estimatefructosamine and glycated hemoglobin levels in newly diagnosed subclinical hypothyroid, clinical hypothyroid and hyper thyroid patients without diabetes mellitus.

Material and Methods: Twenty cases of subclinical hypothyroid,30 cases of hypothyroid,30 cases of hyperthyroid and 30 healthy participantswere included in the study. Fasting plasma glucose and thyroid profile was estimated in suspected cases of thyroid disorder and participants with fasting plasma glucose (FPG) more than $110 \mathrm{mg} / \mathrm{dL}$ were excluded from the study.The participants who were eligible for an inclusion criterion were estimated for fructosamine by nitro bluetetrazolium, (NBT) method andion-exchange high performance liquid chromatography was for glycated hemoglobin.

Results: In Subclinical hypothyroid group there was a statistically significant increase in the mean fasting plasma glucose, fructosamine and glycated hemoglobin levels when compared with the controls. There was a significant increase in the mean fasting plasma glucose,fructosamine and glycated hemoglobin(HbA1c) levels in clinical hypothyroid group when compared with the controls.Pairwise comparison of FPG $(p=0.001)$, fructosamine $(\mathrm{p}=0.001)$ and $\mathrm{HbA1c}(\mathrm{p}=0.001)$ levels with controls showed a statistically significant difference.In clinical hyperthyroid group the mean FPG and HbA1c levels were high and low fructosamine levels when compared with the controls by one way ANOVA.Pairwise comparison of FPG $(\mathrm{p}=0.001)$, fructosamine levels $(\mathrm{p}=0.001)$ and HbA1c ( $\mathrm{p}=0.001)$ levels $(\mathrm{p}=0.001)$ with controls showed a statistically significant difference.
\end{abstract}

Conclusion: Unidentified hyperglycemia could have an impact on thyroid disorder leading to its complication.Hence a systematic approach to fructosamine testing(monitor the plasma glucose concentration over 2-3 weeks) as a routine test in thyroid disorder patients, needs to be considered.Also the management of hyperglycemia in thyroid patients without diabetes mellitus may prove to be beneficial.

Keywords: Fructosamine; glycated haemoglobin; thyroid disorder.

\section{INTRODUCTION}

$\mathrm{H}$ yperthyroidism, hypothyroidism and subclinical hypothyroidism are sequel of altered biochemical function of thyroid gland (1). Thyroid hormones have a major impact on levels of glucose, insulin levels etc., (2). Hence, altered function of thyroid gland disrupts the delicate balance leading to altered glucose levels (3). Impact of increased blood glucose along with alteration in the thyroid gland function leads to inflammatory process, leading to mitochondrial dysfunction (4). Increased glucose levels cause glycation of proteins (5). Examples of these glycated proteins are Glycated Haemoglobin, Fructosamine and Glycated Albumin. These all are produced by non-enzymatic glycation (6). Glycated Hemoglobin assessment (3 month's glucose status) is still the corner stone of assessing glycemic control (7). While Fructosamine is a measure of glycemic index over a short period i.e., 2-3 weeks (8). However, thyroid diseases affect Glycated Hemoglobin levels and hematological facts and Glycated albumin levels are affected by albumin turn over but Fructosamine levels are not affected by $\mathrm{RBC}$ life span (9).

Keeping in this view the following study was undertaken to know the levels of fructosamine in comparison to glycated hemoglobin (ideal glycated status indicator), in non-diabetic newly diagnosed cases of hyperthyroid, clinical hypo and subclinical hypothyroid patients in comparison with normal individuals. This study may help clinician to consider Fructosamine as a marker of glycemic status in the thyroid disorder patients.Estimation and comparison of serum levels of fructosamine and glycated hemoglobin levels in newly diagnosed subclinical hypothyroid, clinical hypothyroid, clinical hyper thyroid patients without diabetes mellitus and healthy participants. 


\section{MATERIALS AND METHODS}

This observational cross-sectional study was conducted between January to December 2016.Patients attending medicine outpatient department at KLE'S Dr. Prabhakar Kore Hospital and Medical Research Centre,Belagavi were study participants.

\section{Sample size calculation}

Following formula was used to calculate the sample size:

Sample size (n) - 4S.D/d ${ }^{2}$

S.D- Standard Deviation, d - error

Considering the Mean \pm S.D. values from previous studies taking 95\% confidence limit and $5 \%$ tolerance level along with error as 3. Sample size in subclinical thyroid patients were 19, clinical hypothyroid and hyperthyroid patients were 26. However for our convenience we took 20 cases of subclinical hypothyroid, 30 cases of clinical hypo and hyperthyroid patients and 30 normal subjects. This sample size was achieved by simple random sampling.

\section{Inclusion criteria}

- Newly diagnosed subclinical hypothyroid patients

- Newly diagnosed hypo and hyperthyroid patients

- Age 20-60 years

\section{Exclusion criteria}

- Diagnosed cases of diabetes mellitus

- Diagnosed cases of thyroid disorder who are on anti thyroid treatment

- Hemolyzed samples

\section{Study protocol}

Ethical committee clearance was obtained (Ref:MDC/DOME/437 dated on $18^{\text {th }}$ November 2016)

Suspected cases of thyroid disorders aged 20-60 years,coming to Medicine outpatient Department of
KLE'S Dr Prabhakar Kore Hospital and Medical Research Centre, Belagavi,were explained about the study in detail and requested to fill the written consent form and proforma $(n=152)$.

$5 \mathrm{ml}$ of Fasting blood was collected from the participants $(n=152)$ taking aseptic precautionary measures using disposable syringe. Then the blood was transferred into two plasma separating test tubes. $3 \mathrm{ml}$ of blood was used for estimating TSH, $\mathrm{T}_{3}$ and $\mathrm{T}_{4}$ levels by Chemiluminescence Immunoassay method (10) and $2 \mathrm{ml}$ was for estimating glucose by GOD-PAP Trenders kit method (11). All the estimations were done at calibrated instruments of KLE'S Dr Prabhakar Kore Hospital and Medical Research Centre, Belagavi at NABL accredited HiTech laboratory.

Hyperbilirubinemic and hemolysed samples $(n=6)$, Subjects on antithyroid treatment $(n=6)$ and with normal thyroid profile and FPG Levels $\geq 110 \mathrm{mg} / \mathrm{dl}$ were excluded from the study $(n=12)$.

Included participants details are in the form of consort (Fig. 1).

In participants, FPG and thyroid profile was done who attended the OPD of Medicine Department belonging to KLE'S Dr Prabhakar Kore Hospital and Medical Research Centre,of this 12 were excluded as they Diabetic (FPG $\geq 110$ ) and normal thyroid profile.Rest of the participants were categorized into 4 groups.

1. Controls $(n=30)$

2. Subclinical hypothyroidism $(\mathrm{n}=20)$

3. Clinical hypothyroidism $(n=30)$

4. Clinical hyperthyroidism $(n=30)$

Then from the included participants $3 \mathrm{ml}$ blood was collected under aseptic precautionary measures using disposable syringe in EDTA tube for HbA1c and $2 \mathrm{ml}$ blood in plain tubes for fructosamine estimation.

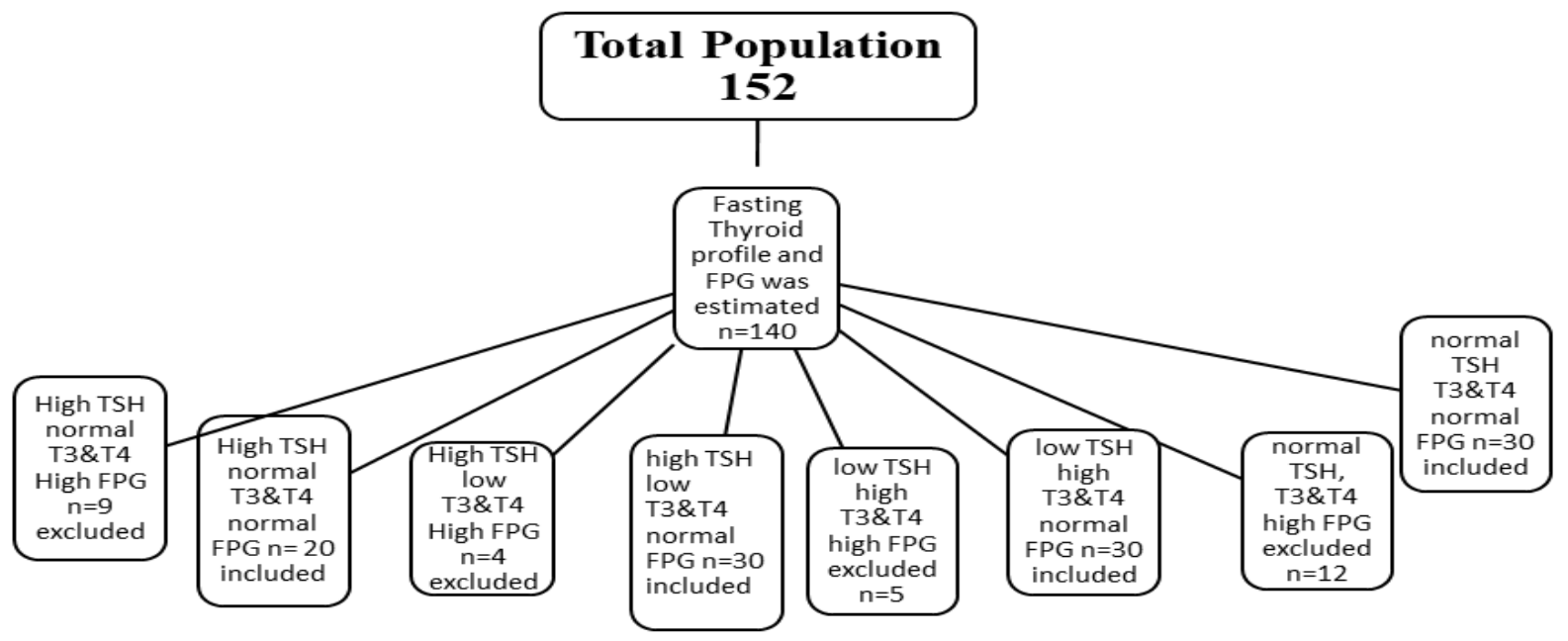

Fig. 1: Consort 
Methodology for the Estimation of HbA1c and Fructosamine

\section{HbA1c estimation}

The estimation of Glycated Hemoglobin was done by ion-exchange high performance liquid chromatography (HPLC; 12).

\section{Fructosamine estimation}

The estimation of serum fructosamine was done by nitro blue tetrazolium NBT method (13).

\section{Statistical analysis}

The data was entered into excel sheet

Data analysis was done by using software package of social Sciences (SPSS) trial version 20.All the numerical values were summarised as Mean \pm SD with $\mathrm{p}<0.05$ considered as level of significance.
- One way ANOVA and pairwise comparisons of FPG, fructosamine and HbA1c levels by Tukey's multiple Post-hoc Bonferroni test

- Comparison of means of several groups.

To know the significant difference in the means of variables:-

$>$ Between controls and subclinical hypothyroid group

$>$ Between controls and clinical hypothyroid group

$>$ Between controls and clinical hyperthyroid group

\section{RESULTS}

110 eligible participants aged between 20-60 years were enrolled in our study.

Graphs 1 and 2 show the details of eligible participants.

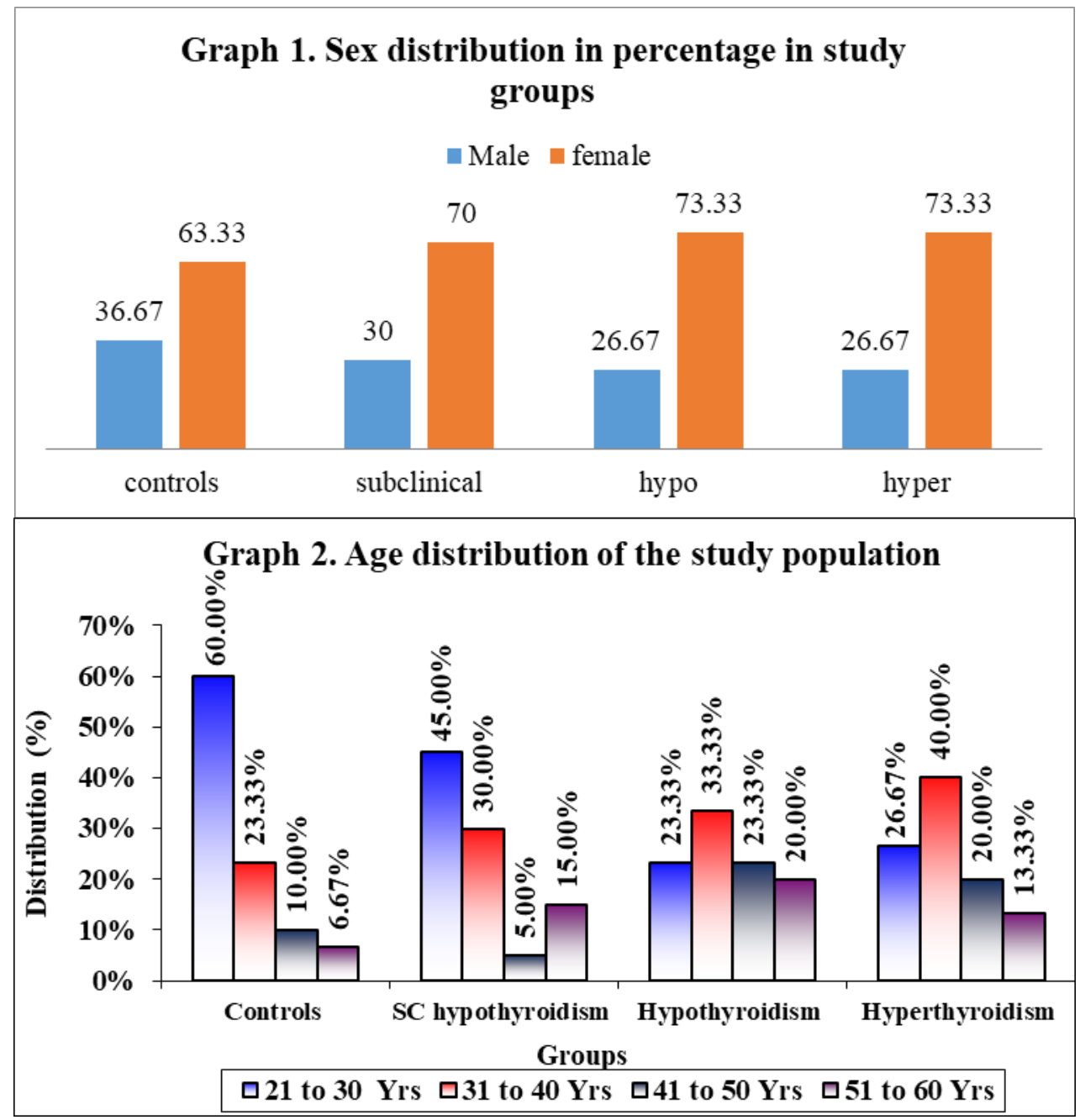

Graph 1 represents that most of the participants were females and Graph 2 shows most of our participants were aged 21- 30 years,followed by 31-40 years.

Table 1: Comparison of mean thyroid profile, fasting plasma glucose, fructosamine and HbA1c levels in our study participants

\begin{tabular}{|c|c|c|c|c|c|c|}
\hline Variables & $\begin{array}{c}\text { Healthy } \\
\text { Controls } \\
\mathbf{n = 3 0}\end{array}$ & $\begin{array}{c}\text { Subclinical } \\
\text { Hypothyroid } \\
\mathbf{n = 3 0}\end{array}$ & $\begin{array}{c}\text { Clinical } \\
\text { Hypothyroid } \\
\mathbf{n = 3 0}\end{array}$ & $\begin{array}{c}\text { Clinical } \\
\text { hyperthyroid } \\
\mathbf{n}=\mathbf{3 0}\end{array}$ & $\begin{array}{c}\mathbf{F} \\
\text { Value }\end{array}$ & $\begin{array}{c}\mathbf{P} \\
\text { Value }\end{array}$ \\
\hline $\mathbf{T S H}(\boldsymbol{\mu} \mathbf{I U} / \mathbf{m l})$ & $2.32 \pm 0.70$ & $13.85 \pm 8.70$ & $56.81 \pm 47.05$ & $0.19 \pm 0.15$ & 33.56 & 0.001 \\
\hline $\mathbf{T}_{\mathbf{3}(\mathbf{n g} / \mathbf{m l})}$ & $1.05 \pm 0.36$ & $0.91 \pm 0.29$ & $0.71 \pm 0.82$ & $10.76 \pm 7.53$ & 45.00 & 0.001 \\
\hline
\end{tabular}




\begin{tabular}{|c|c|c|c|c|c|c|}
\hline $\mathbf{T}_{\mathbf{4}}(\boldsymbol{\mu g} / \mathbf{d l l})$ & $7.90 \pm 2.18$ & $7.57 \pm 1.89$ & $2.18 \pm 0.95$ & $16.33 \pm 8.21$ & 49.54 & 0.001 \\
\hline FPG(m/dl) & $85.40 \pm 4.84$ & $88.80 \pm 2.59$ & $89.23 \pm 4.44$ & $93.67 \pm 0.92$ & 26.037 & 0.001 \\
\hline Fructosamine( $\boldsymbol{\mu m o l} / \mathbf{L})$ & $361.30 \pm 7.88$ & $485.35 \pm 40.16$ & $576.77 \pm 37.23$ & $269.43 \pm 7.90$ & 761.92 & 0.001 \\
\hline HbA1c(\%) & $4.84 \pm 0.36$ & $5.32 \pm 0.38$ & $5.44 \pm 0.14$ & $5.53 \pm 0.24$ & 34.55 & 0.001 \\
\hline
\end{tabular}

Table 2: Pairwise comparisons of FPG, Fructosamine and HbA1c levels by Tukey's multiple Post-hoc Bonferroni test

\begin{tabular}{|c|c|c|c|}
\hline Variables & $\begin{array}{c}\text { Subclinical } \\
\text { hypothyroid }\end{array}$ & Clinical hypothyroid & $\begin{array}{c}\text { Clinical } \\
\text { hyperthyroid }\end{array}$ \\
\hline Control (FPG) & $\mathrm{p}=0.001^{*}$ & $\mathrm{p}=0.009^{*}$ & $\mathrm{p}=0.001^{*}$ \\
\hline $\begin{array}{c}\text { Control } \\
\text { (Fructosamine) }\end{array}$ & $\mathrm{p}=0.001^{*}$ & $\mathrm{p}=0.001^{*}$ & $\mathrm{p}=0.001^{*}$ \\
\hline Control (HbA1c) & $\mathrm{p}=0.001^{*}$ & $\mathrm{p}=0.001^{*}$ & $\mathrm{p}=0.001^{*}$ \\
\hline
\end{tabular}

\section{DISCUSSION}

In thyroid dysfunctions the glucose homeostatic balance is broken.Increased concentration of $\mathrm{T}_{3}$ causes protein catabolism and pessimistic nitrogen balance.Circulating sugars mainly glucose and fructose form Advanced Glycation End Products(AGEs) when they come in contact with proteins and lipids.Examples of proteins subject to non-enzymatic glycation are glycated hemoglobin, and Fructosamine.There is a wellrecognised positive association between thyroid disorders and diabetes mellitus. There are lack of studies to correlate the effects of thyroid hormones on glycation.Fructosamine, indicate short term glycemic control.Hence this study was undertaken to estimate the glycated haemoglobin and fructosamine levels in clinical hypo and hyperthyroid patients without diabetes mellitus along with apparently healthy controls.

\section{Subclinical hypothyroidism}

In the present study the mean FPG, HbAlc and Fructosamine levels were statistically significant when compared with the controls. These findings are in accordance with one of the study done in south Karnataka (14).

\section{Clinical hypothyroidism}

Higher levels of FPG in clinical hypothyroid cases when compared with the controls and were statistically significant $(p<0.05)$. However the levels were in the normoglycemic range. The fructosamine levels were greatly increased in clinical hypothyroid patients when compared with the controls which was statistically significant. This is in accordance with many previous studies done in south Karnataka and North India $(14,4)$.

In clinical hypothyroidism raised fructosamine values could be due to hypometabolic state as the half -life of plasma proteins are prolonged(due to decreased turn over).It is an inflammatory process, causes creation of free radicals that leads to increased oxidative stress and increased glycation of proteins.Subnormal function of the thyroid gland and insufficient iodination, becomes a major site of a damaging free radical generation. Free radical production deplete the defence mechanisms like glutathione peroxidise. Reduced production of glutathione peroxidise worsens the functioning of the thyroid gland and increases the glycation of proteins(15).

The study done in 2014, in Tamil Nadu, India, proved that in hypothyroidism there is hyperinsulinemia and insulin resistance in peripheral tissue. They observed altered glucose homeostasis thereby causing increased protein glycation. The inclination of glycated proteins in the tissues cause easy proteolysis and being further source of free radicals (16).

\section{Clinical hyperthyroidism}

Higher levels of FPG in clinical hypothyroidism than the control group, however mean fructosamine levels were lower than the control group and were statistically significant. These findings were in accordance with previous studies done in South Karnataka and North India $(14,15)$.

Hyperthyroidism is a hypermetabolic state with increased muscle protein breakdown.There is increased metabolic activity with increased protein turnover, however the fructosamine concentrations were significantly lower in clinical hyperthyroid patients as compared to controls.Also there is a state of oxidative stress which increases the possibility of proteins getting glycated. The higher levels of FPG in hyperthyroid group as compared to normal control groups was due to change in carbohydrate metabolism (14).

The study done in North Indian population showed that the effect of thyroid hormone $\left(\mathrm{T}_{3}\right)$ cause glycogenesis,gluconeogenesis,increased hepatic expression of glucose transporter (GLUT2) and hepatic glucose output.Increased all of these lead to increased output of glucose as thyroid hormones have an impact on epinephrine and glucagon (4).

In previous studies reported, marked decrease in serum fructosamine concentrations in hyperthyroidism patients as compared to controls. They unveiled, instead of decreased concentration of fructosamine and albumin levels there is an increase in $\mathrm{HbA1c}$ level which corresponds to raised glucose 
concentrations. They inferred that, where one class of proteins resist the glycation and the other corresponded to the plasma glucose concentration (17). Altered glucose homeostasis, increase turnover of proteins, impaired oxidative stress balance in hyperthyroidism, this explains the lower Fructosamine levels (14).
Though our study findings are well in support of previous studies, it has got some limitations. It was single centre case-control study. A limited number of cases and controls are included. With such varied results and discussion we tried to put up findings and probable reason behind these findings in the form of a fig. 2.

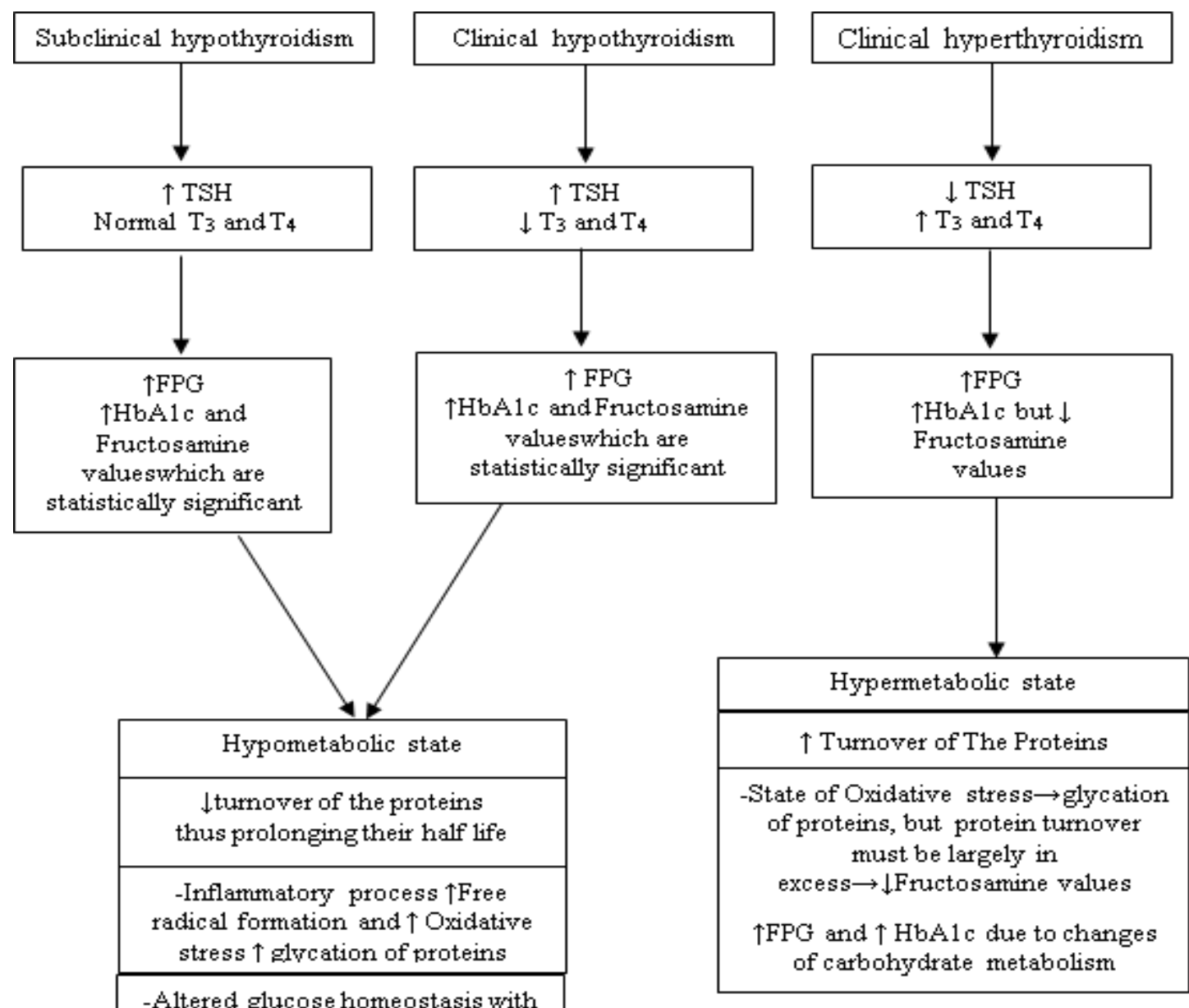

\section{CONCLUSION}

In subclinical and clinical hypothyroid participant's fructosamine and glycated hemoglobin levels were increased compared to normal participants and in case of clinical hyperthyroid individuals Glycated haemoglobin levels were high but fructosamine levels were low compared to normal participants. Probably as thyroid disorders affect metabolic rate of the individuals and this has an impact on protein turnover leading to altered inflammatory state and oxidative stress causing altered levels of fructosamine and glycated hemoglobin.

Therefore, do patients with thyroid disorders without DM be tested for fructosamine, routinely? This needs to be reconfirmed with a better sample size and later appropriate guidelines should be laid down.
However, considering that the patients in our study were newly diagnosed cases of thyroid disorder and were showing altered glucose levels(trend towards increased level),this emphasizes the need for definitive guidelines for treating the patients of thyroid disorder for hyperglycemia.

\section{Limitations}

Small sample size and follow up of the thyroid patients after treatment was not done.

\section{ACKNOWLEDGEMENT}

We acknowledge ICMR for providing a research grant for the study (No: NO.3/2/March-2016/PGThesis HRD(4).

\section{CONFLICT OF INTEREST}

Authors declare no conflict of Interest. 


\section{REFERENCES}

1. Surks, M. I., Ortiz, E., Daniels, G. H., Sawin C.T, Col F. N, Cobin, H. R., et al., Subclinical thyroid disease: scientific review and guidelines for diagnosis and management. JAMA. 2004; 291(2): 228-238. doi:10.1001/jama.291.2.228

2. Raboudi, N., Arem, R., Jones, R. H., Chap, Z., Pena, J., Chou, J., et al., Fasting and postabsorptive hepatic glucose and insulin metabolism in hyperthyroidism. Am J Physiol. 1989; 256(1 Pt 1): E159-E166. doi:10.1152/ ajpendo. 1989.256.1.E159 [Pubmed]

3. Weinstein, S. P., O'Boyle, E., Fisher, M., Haber, R. S. Regulation of GLUT2 glucose transporter expression in liver by thyroid hormone: evidence for hormonal regulation of the hepatic glucose transport system. Endocrinology. 1994; 135(2): 649-654. doi:10.1210/endo.135.2.8033812 [Pubmed]

4. Sohal, S., Wats, A., Vij, C. Evaluation of Glycosylated Hemoglobin(HbA1c) Levels in Hypothyroid and Hyperthyroid Patients. Annals of Applied Biosciences 2016; 3(1): 101-107.

5. Koga, M., Murai, J., Saito, H., Matsumoto, S., Kasayama, S. Effects of thyroid hormone on serum glycated albumin levels: study on non-diabetic subjects. Diabetes Res Clin Pract. 2009; 84(2): 163-167. doi:10.1016/j.diabres. 2009.01.013

6. Vasudevan, D. M., Shreekumari, S. Section 2. General Metabolism Regulation of blood Glucose , Insulin and Diabetes Melittus, Text Book of Biochemistry for Medical students , 9 th Ed.Jaypee Brothers medical Publishers(p)Ltd, New delhi, 2019: p -178.

7. Anantarapu, S., Vaikkakara, S., Sachan, A., Phaneendra, B.V., Suchitra, M. M., Reddy, A. P., et al., Effects of thyroid hormone replacement on glycated hemoglobin levels in nondiabetic subjects with overt hypothyroidism. Arch Endocrinol Metab. 2015; 59(6): 495-500. doi:10.1590/23593997000000065

8. Hara, H., Ban, Y., Taniyama, M., Sato, R., Kushima, K., Nagakura, H., et al., The significance of serum fructosamine measurement in patients with thyroid diseases. Nihon Naibunpi Gakkai Zasshi. 1990; 66(10): 1075-1084.

9. Alarcon-Casas, L.W., Hirsch, I. B. The challenge of the use of glycemic biomarkers in diabetes: reflection of HemoglobinA1C, 1,5-androhydroglycitol and the glycated proteins, fructosamine and glycated albumin.Diabetic Spectrum. 2011; 2593: 141-148.

10. Kazerouni, F., Amirrasouli, H. Performance characteristics of three automated immunoassays for thyroid hormones. Caspian J Intern Med. 2012; 3(2): 400-404.

11. Chu, S. Y., Chenug, P. Experience with BoeringerMamheim GOD-PAP.Clinical Biochemistry. 1978: 187-189.

12. Khan, H., Rabeya, R., Saiedullah, M. Measurements of HbA1c by High performance Liquid chromatography by D10 analyser and immunological method by Beckman coulter method AU480 system:A comparative study, JEnam Med Col. 2012; 2(2): 62-66.

13. Mashiba, S., Uchida, K., Okuda, S, Tomita, S. Measurement of glycated albumin by the nitro blue tetrazolium colorimetric method. Clin Chim Acta. 1992; 212(1-2): 3-15. doi:10.1016/0009-8981(92)90133-b

14. Udupa, V. S., Manjrekar, A. P., Udupa, A. V., D’Souza, V. Fructosamine and Lipids in Subclinical Hypothyroidism. Journal of Clinical and Diagnostic Research. 2013; 7(1): 1822.

15. Soni, N., Kaushik, G. G., Sharma, N. Biochemical role of serum fructosamine in patients with thyroid disorders. Natl $\mathbf{J}$ Physiol Pharm Pharmacol. (2015), [cited February 15, 2020]; 5(1): 50-53. doi:10.5455/njppp.2015.5.290720141

16. Kondaveeti, S. G., Bhanu Prakash, I. Anand Shaker. Estimation Of Glycated Albumin Levels In Various Thyroid Disorders Ijcrr. 2014; 06(09): 138-144.
17. Sharma, A. K., Pareek, U. K., Dudhane, M. N., Gupta, G. S. Status of serum fructosamine in hyperthyroid subjects in Udaipur, Rajasthan. Int J Pharm Sci Res 2017; 8(1): 312315. doi: 10.13040/IJPSR.0975-8232. 